\title{
Emulsification of Indian heavy crude oil using a novel surfactant for pipeline transportation
}

\author{
Shailesh Kumar $^{1} \cdot$ Vikas Mahto $^{1}$
}

Received: 1 June 2016/Published online: 12 April 2017

(c) The Author(s) 2017. This article is an open access publication

\begin{abstract}
The most economical way to overcome flow assurance problems associated with transportation of heavy crude oil through offshore pipelines is by emulsifying it with water in the presence of a suitable surfactant. In this research, a novel surfactant, tri-triethanolamine monosunflower ester, was synthesized in the laboratory by extracting fatty acids present in sunflower (Helianthus annuиs) oil. Synthesized surfactant was used to prepare oil-in-water emulsions of a heavy crude oil from the western oil field of India. After emulsification, a dramatic decrease in pour point as well as viscosity was observed. All the prepared emulsions were found to be flowing even at $1{ }^{\circ} \mathrm{C}$. The emulsion developed with $60 \%$ oil content and $2 \mathrm{wt} \%$ surfactant showed a decrease in viscosity of $96 \%$. The stability of the emulsion was investigated at different temperatures, and it was found to be highly stable. The effectiveness of surfactant in emulsifying the heavy oil in water was investigated by measuring the equilibrium interfacial tension (IFT) between the crude oil (diluted) and the aqueous phase along with zeta potential of emulsions. $2 \mathrm{wt} \%$ surfactant decreased IFT by almost nine times that of no surfactant. These results suggested that the synthesized surfactant may be used to prepare a stable oil-in-water emulsion for its transportation through offshore pipelines efficiently.
\end{abstract}

Vikas Mahto

vikas.ismpe@hotmail.com

1 Department of Petroleum Engineering, Indian Institute of Technology (Indian School of Mines), Dhanbad, Jharkhand, India

Edited by Yan-Hua Sun
Keywords Heavy crude oil · Oil-in-water emulsion · Pipeline transportation · Sunflower oil · Rheology · Stability

\section{Introduction}

In past decades, a progressive decrease in conventional oil reserves has led to a dramatic increase in production of heavy crude oil. However, transportation of such highly viscous crude oil through pipelines is a major challenge for petroleum industries especially in offshore conditions. Heavy crude oils have viscosities of more than $1000 \mathrm{mPa} \mathrm{s}$ at room temperature. However, viscosity of crude oil should be less than $200 \mathrm{mPa} s$ at $15{ }^{\circ} \mathrm{C}$ for its transportation through pipelines (Kessick and Denis 1982). The flowability of crude oil at the pumping temperature is an important factor that affects pipeline transportation. Heavy crudes usually have higher pour points due to high content of high molecular weight components, such as waxes, asphaltenes and resins. In conditions where the atmospheric temperature is below the pour point, crude oil gels completely and causes severe transportation problems. Especially in the cold offshore environment, waxes and asphaltenes deposit over inner surfaces of pipelines and eventually clog the pipelines, which further increases the pumping cost.

Therefore, several methods are employed by petroleum industries to transport crude oils through pipelines, dilution/blending of crude with lighter oil or organic solvents, preheating of crude and subsequent heating of pipelines, use of pour point depressants (PPDs), application of drag reducing additives and development of core annular flow (CAF) and in situ oil upgrading (Martínez-Palou et al. 2011). However, each of these methods has economic, 
technical and logistical drawbacks when it comes to transportation of heavy crude oil through offshore pipelines. Another pipeline technique favourable for cold offshore environments is the transportation of heavy crudes as oil-in-water $(\mathrm{O} / \mathrm{W})$ emulsions.

Oil-in-water emulsions are thermodynamically unstable dispersions of the oil phase in the water phase. They are subjected to several breakdown processes like flocculation, coalescence, Ostwald ripening and creaming (Langevin et al. 2004). In order to make these emulsions kinetically stable, a suitable surfactant (or mixture of surfactants) is always added, which adsorbs at the oil/water interface and forms a strong interfacial film (Jiang et al. 2013). However, a particular surfactant may not be suitable for different crude oils due to variation in physicochemical properties. Fatty acids (FAs), derived from different vegetable oils, are raw materials for preparation of surfactants through esterification or polymerization. Surfactants synthesized using vegetable oils have various advantages. They are cheaper, biodegradable and cause no adverse effect on nature. In this study, we used sunflower oil to synthesize a novel surfactant. Sunflower oil is a triglyceride obtained from pressing sunflower (Helianthus annuus) seeds. Alkaline hydrolysis of these triglycerides produces FAs and glycerol. Fatty acids from sunflower oil consist of $6.8 \%$ palmitic, $5.0 \%$ stearic, $19.6 \%$ oleic and $68.6 \%$ linoleic acids (Harrington and D'Arcy-Evans 1985). Hydrolysed sunflower oil was esterified with a trimer of triethanolamine to develop a new surfactant as ester and further evaluated as emulsifier for preparation of heavy oil-in-water emulsions. The estimated cost of the synthesized surfactant is very low as compared to the cost of commercial surfactants. Considering the economy, it is very important for petroleum industries to maximize the oil content as well as minimize the requirement of surfactant to prepare a stable emulsion with acceptable viscosity and pour point.

The objective of current research is to synthesize a cheap natural surfactant from sunflower oil that is suitable for preparing an oil-in-water emulsion of an Indian heavy crude oil to facilitate its transportation through offshore pipelines. Oil content and the amount of surfactant required were further optimized by investigating their effect on pour point, viscosity, stability, droplet size distribution, interfacial tension and zeta potential of the prepared emulsions.

\section{Experimental}

\subsection{Materials}

Heavy crude oil sample was collected from a Rajasthan oil field, India. Sunflower oil was procured from a local market in Kolkata, India. Polythene ethylene glycol (PEG) and triethanolamine (TEA) were obtained from Loba Chemie Pvt. Ltd. (Mumbai, India). n-heptane, $n$-decane, toluene, $\mathrm{HCl}$ and chloroform were procured from Merck Specialties Pvt. Ltd. (Mumbai, India). Methanol, sodium chloride, sodium carbonate, acetone, $p$-toluene sulphonic acid, acetic acid, petroleum ether $\left(40-60^{\circ} \mathrm{C}\right)$ and acetonitrile were received from Avantor Performance Materials India Ltd. (New Delhi, India).

\subsection{Synthesis of surfactant}

Hydrolysis of sunflower oil (SO) Sunflower oil (50 g) was reacted with $10 \% \mathrm{NaOH}$ solution $(250 \mathrm{~mL})$ at $150{ }^{\circ} \mathrm{C}$ under constant stirring $(450 \mathrm{rpm})$ in a three-necked flask along with gradual addition of water $(400 \mathrm{~mL})$ for $2 \mathrm{~h}$. After reaction, a hot solution of $30 \% \mathrm{HCl}(150 \mathrm{~mL})$ was added and the mixture was kept in a water bath at $80^{\circ} \mathrm{C}$ until the oily layer became clear. The oily layer was then separated and collected as hydrolysed sunflower oil (HSO), a mixture of several free fatty acids.

Synthesis of tri-triethanolamine TEA (149 g) was condensed in the presence of $\mathrm{NaOH}(1.6 \mathrm{~g})$ as a catalyst. The reaction was carried at $260{ }^{\circ} \mathrm{C}$ under constant stirring $(450 \mathrm{rpm})$ in a three-necked flask until $36 \mathrm{~g}$ of water was collected in a Dean and Stark trap. The used catalyst was then neutralized by washing the obtained product with $5 \%$ acetic acid solution. To further wash out impurities, the product was dissolved in petroleum ether (b.p. $40-60{ }^{\circ} \mathrm{C}$ ) and an organic layer was separated. The remaining solvent was distilled off using a Soxhlet apparatus to give tri-triethanolamine (TTEA) (Hafiz and Abdou 2003).

Esterification of HSO and TTEA HSO (36 g) was reacted with TTEA $(51 \mathrm{~g})$ in the presence of a catalyst, $p$ toluene sulphonic acid $(0.0108 \mathrm{~g})$. The reaction was carried at $150{ }^{\circ} \mathrm{C}$ with continuous stirring, and water was removed azeotropically as it was formed. The product was then washed with a hot solution of $5 \% \mathrm{Na}_{2} \mathrm{CO}_{3}$ to remove the catalyst and then dissolved in petroleum ether (b.p. $40-60{ }^{\circ} \mathrm{C}$ ). After separating the organic layer, the solvent was distilled off to obtain purified tri-triethanolamine monosunflower ester (TMSE) as a desired surfactant (Hafiz and Abdou 2003). Physical state of the surfactant is semisolid at $25{ }^{\circ} \mathrm{C}$ and brownish-black in colour. It has a density of $1.102 \mathrm{gm} / \mathrm{cm}^{3}$ at $15^{\circ} \mathrm{C}$.

\subsection{Characterization of crude oil}

Heavy crude oils are usually produced in the form of waterin-oil emulsion (Dicharry et al. 2006), so the initial water content in crude oil was measured using the Dean and Stark method (ASTM D4006-11 2011). Water was then separated with aid of a commercial demulsifier (PEG 200) and 
heating to obtain pure heavy crude oil. Further, the density (ASTM D1480-15 2015) and pour point (ASTM D5853-11 2011) of the heavy crude oil were also determined using standard ASTM methods. SARA analysis was performed to characterize crude into four major components: saturates, aromatics, resins and asphaltenes (Jha et al. 2014). Wax content was determined using the modified Universal Oil Products (UOP) 46-64 method (Sharma et al. 2014), and wax appearance temperature (WAT) was determined using the viscosity method (Dantas Neto et al. 2009).

\subsection{Preparation of emulsions}

An aqueous phase was first prepared by dissolving the surfactant in distilled water at $65{ }^{\circ} \mathrm{C}$. The heavy crude oil sample was preheated to $65{ }^{\circ} \mathrm{C}$ to improve its fluidity before adding it to the aqueous phase. Emulsions were then prepared using a Hielscher ultrasonic homogenizer with an UP200Ht processor at a working frequency of $26 \mathrm{kHz}$ and $100 \%$ amplitude for a fixed irradiation time of $10 \mathrm{~min}$. In this study, the oil content was varied in the emulsion, keeping the volume of the surfactant constant $(2 \mathrm{wt} \%)$ with respect to the total volume of the emulsion. Again for specific series of experiments, at the optimized oil content, the surfactant concentration in the emulsion was varied to obtain an optimum surfactant concentration.

\subsection{Fourier transform infrared (FT-IR) spectroscopy}

Infrared spectra of both crude oil and the synthesized surfactant were recorded using a Perkin-Elmer spectrum 2 spectrophotometer assisted by Spectrum-10 software to analyse the functional groups present. Software collected spectra, in absorbance mode, in the spectral region of from 4000 to $400 \mathrm{~cm}^{-1}$. Further infrared spectra of emulsion systems were also recorded to compare and analyse the functional groups.

\subsection{Measurement of pour point and rheology of the crude oil and emulsions}

The main objective of the emulsification process is to decrease the pour point and enhance the flowability of the heavy crude oil. Pour points of emulsions were measured using the ASTM method (ASTM D5853-11 2011). The rheological flow behaviour of crude oil and emulsions was investigated at $25{ }^{\circ} \mathrm{C}$ using a Bohlin Gemini 200 rheometer (Gemini 200 software), supplied by Malvern instruments. Cone-plate $\left(25-\mathrm{mm}\right.$ plate diameter, $2.5^{\circ}$ cone angle and $70-\mu \mathrm{m}$ gap) and parallel-plate $(25-\mathrm{mm}$ plate diameter at two gaps, 750 and $500 \mu \mathrm{m})$ geometries were used for measurement of rheology of the crude oil and prepared emulsions, respectively.

\subsection{Measurement of emulsion stability}

Immediately after preparation of emulsions, each emulsion was transferred to three separate $10-\mathrm{mL}$ glass tubes $(0.1-$ $\mathrm{mL}$ graduation) and tightly stoppered with a glass lid. These three separate groups of emulsion samples were then kept at 15,25 and $35^{\circ} \mathrm{C}$ to allow separation of water over time from these emulsion samples. The amount of water separated at the end of six days was noted and the emulsion stability was calculated using the following equation.

$S=\left(1-V / V_{\mathrm{i}}\right) \times 100 \%$

where $S$ is the emulsion stability; $V_{\mathrm{i}}$ is the water volume in the initial emulsion, $\mathrm{mL}$; and $V$ is the volume of water separated from the emulsion, $\mathrm{mL}$.

\subsection{Interfacial tension and zeta potential measurements}

A Texas-500 spinning drop tensiometer (Data-Physics, Model No: SVT $15 \mathrm{~N}$ ) was used to measure interfacial tension (IFT) between the oil and the aqueous phase at different surfactant concentrations at $25{ }^{\circ} \mathrm{C}$. Due to the very high viscosity of the crude oil, it was impossible to inject a drop of oil using a microlitre syringe in the capillary tube filled with the aqueous phase. Therefore, crude oil had to be diluted with $n$-decane $(40 \% \mathrm{v} / \mathrm{v})$ to make it flowable (Zhao et al. 2013). During measurement, the capillary tube was rotated at $2000 \mathrm{rpm}$ for $600 \mathrm{~s}$ to obtain equilibrium IFT values.

Zeta potential of emulsions was measured using a ZetaMeter System 4.0 (Zeta-meter, INC., Staunton, VA) to study the charge properties of oil droplets in the emulsion at room temperature. To prepare samples for measurement, $0.1 \mathrm{~mL}$ of each emulsion was diluted with $100 \mathrm{~mL}$ of distilled water. At least five different particles of each sample were tracked to obtain the average value of zeta potential.

\subsection{Measurements of oil droplet size and size distribution}

Size and distribution of oil droplets in prepared emulsions were determined using a Zetasizer Nano S90 particle size analyser procured from Malvern Instruments Ltd. at $25^{\circ} \mathrm{C}$. Dynamic light scattering was conducted at a $90^{\circ}$ scattering angle to measure particle sizes with this particle size analyser. This instrument analyses the diffusion of particles moving under Brownian motion by measuring the scattered light intensity and converts this to size and a size 
distribution using the Stokes-Einstein relationship. In order to make the emulsion sample optically clear and to avoid the effect of multiple scattering, $0.1 \mathrm{~mL}$ of emulsion was diluted with $15 \mathrm{~mL}$ of distilled water. Tests were run three times, and the test duration was shortened to $10 \mathrm{~s}$ to avoid effect of coalescence of droplets during measurement.

\section{Results and discussion}

In the present investigation, a surfactant was synthesized by extracting free fatty acids from sunflower oil and evaluated as an emulsifier. Oil-in-water emulsions were prepared to optimize oil content and surfactant concentration by investigating their effects on pour point, rheology and stability of emulsions. Effects of droplet size distribution in emulsions on their viscosity and stability were also examined along with discussion of interfacial properties, IFT and zeta potentials of emulsions at various surfactant concentrations.

\subsection{Analysis of crude oil}

The results of water content, API gravity, pour point, wax content, WAT and SARA analysis of crude oil are reported in Table 1. The Dean and Stark method confirmed the presence of a large amount $(45 \%)$ of dispersed water in the crude oil (W/O emulsion) sample. API gravity of heavy crude oil is $21.27^{\circ}$, so it can be classified as heavy crude oil according to API convention. A large amount of wax is present in heavy crude oil, which is a major factor in resisting flow as these wax crystals start appearing at temperature around $55{ }^{\circ} \mathrm{C}$. These wax crystals grow at further decreasing temperatures, start to precipitate and form a solid phase. A very high pour point $\left(42^{\circ} \mathrm{C}\right)$ was observed for this particular heavy crude oil which can be

Table 1 Physicochemical properties of heavy crude oil

\begin{tabular}{lll}
\hline Parameter & Observed value & Method \\
\hline Water content, \% (v/v) & 45 & ASTM D4006-11 \\
Density at $15{ }^{\circ} \mathrm{C}, \mathrm{g} \mathrm{cm}^{-3}$ & 0.9254 & ASTM D1480-15 \\
Specific gravity at $15{ }^{\circ} \mathrm{C}$ & 0.9262 & ASTM D1480-15 \\
API gravity at $15{ }^{\circ} \mathrm{C}$ & 21.27 & \\
Pour point, ${ }^{\circ} \mathrm{C}$ & 42 & ASTM D5853-11 \\
Wax content, \% (w/w) & 11 & Modified UOP 46-64 \\
WAT, ${ }^{\circ} \mathrm{C}$ & 55 & Viscosimetry \\
SARA analysis, \% (w/w) & & \\
Saturates & 66.5 & \\
Aromatics & 10.5 & \\
Resins & 8.5 & \\
Asphaltenes & 6.5 & \\
\hline
\end{tabular}

attributed to its high wax content. As reported, the crude oil was found to be highly asphaltinic in nature and very rich in the resin fraction, which makes crude oil heavier and restricts its flowability. A very high fraction of saturates $(66.5 \%)$ was present in crude oil, which provides an asphaltene-hostile environment and assists in deposition of asphaltenes (Alcazar-Vara and Buenrostro-Gonzalez 2011).

\subsection{Infrared spectroscopic analysis}

FT-IR spectra of heavy crude oil, TMSE and O/W emulsion are shown in Fig. 1, and the observed peaks with associated functional groups are given in Table 2. Characteristic peaks of alkyl groups $\left(\mathrm{CH}_{3}\right.$ and $\left.\mathrm{CH}_{2}\right)$ due to stretching vibration and bending vibration with strong absorbance at 2919, 2850 and $1462 \mathrm{~cm}^{-1}$ were observed for heavy crude oil. Such high absorbance can be attributed to high contents of saturates and wax in heavy crude oil. Combination of the multiple bands around $1114 \mathrm{~cm}^{-1}$ and the band at $1736 \mathrm{~cm}^{-1}$ confirms the presence of ester in the synthesized surfactant. Presence of aromatic nuclei observed in the crude oil may be due to the presence of asphaltenes and resins (Quiroga-Becerra et al. 2012). Peaks around 719 and $666 \mathrm{~cm}^{-1}$ in heavy crude oil and TMSE, respectively, represent rocking vibration of the backbone of carbon chains having six or more carbon atoms (QuirogaBecerra et al. 2012). In spectra of the emulsion system, a very strong and broad absorption band at $3443 \mathrm{~cm}^{-1}$ was observed due to the presence of hydroxyl groups from $\mathrm{H}_{2} \mathrm{O}$ after formation of the $\mathrm{O} / \mathrm{W}$ emulsion. The absorption bands of alkyl groups were greatly weakened, suggesting the breaking of $\mathrm{C}-\mathrm{C}$ bonds and shortening of $\mathrm{C}$-chains thus improving the flowability of heavy crude oil. Also the band due to rocking vibration of C-chains shifted to $495 \mathrm{~cm}^{-1}$ that can also suggest that the number of $\mathrm{C}$-atoms in the chain has been reduced due to emulsion formation.

\subsection{Depression in pour point}

In order to avoid flow assurance problems in pipelines under offshore conditions, the pour point of emulsions should be very low. Ahmed et al. (1999) found the pour point to be 6 and $9{ }^{\circ} \mathrm{C}$, respectively, for emulsions with oil content of $60 \%$ and $70 \%$, respectively, when the pour point of the crude oil was $18{ }^{\circ} \mathrm{C}$. Zaki (1997) also reported a decrease in the pour point of crude oil from 13 to $7{ }^{\circ} \mathrm{C}$ after emulsification with $70 \%$ oil content. Pour point is a very important flow parameter, and for all the prepared emulsions in our study, the measured pour point was found to be remarkably low compared to the pour point of heavy crude oil $\left(42{ }^{\circ} \mathrm{C}\right)$. All the emulsions prepared were flowing at even $1{ }^{\circ} \mathrm{C}$, which is highly suitable for offshore conditions. 


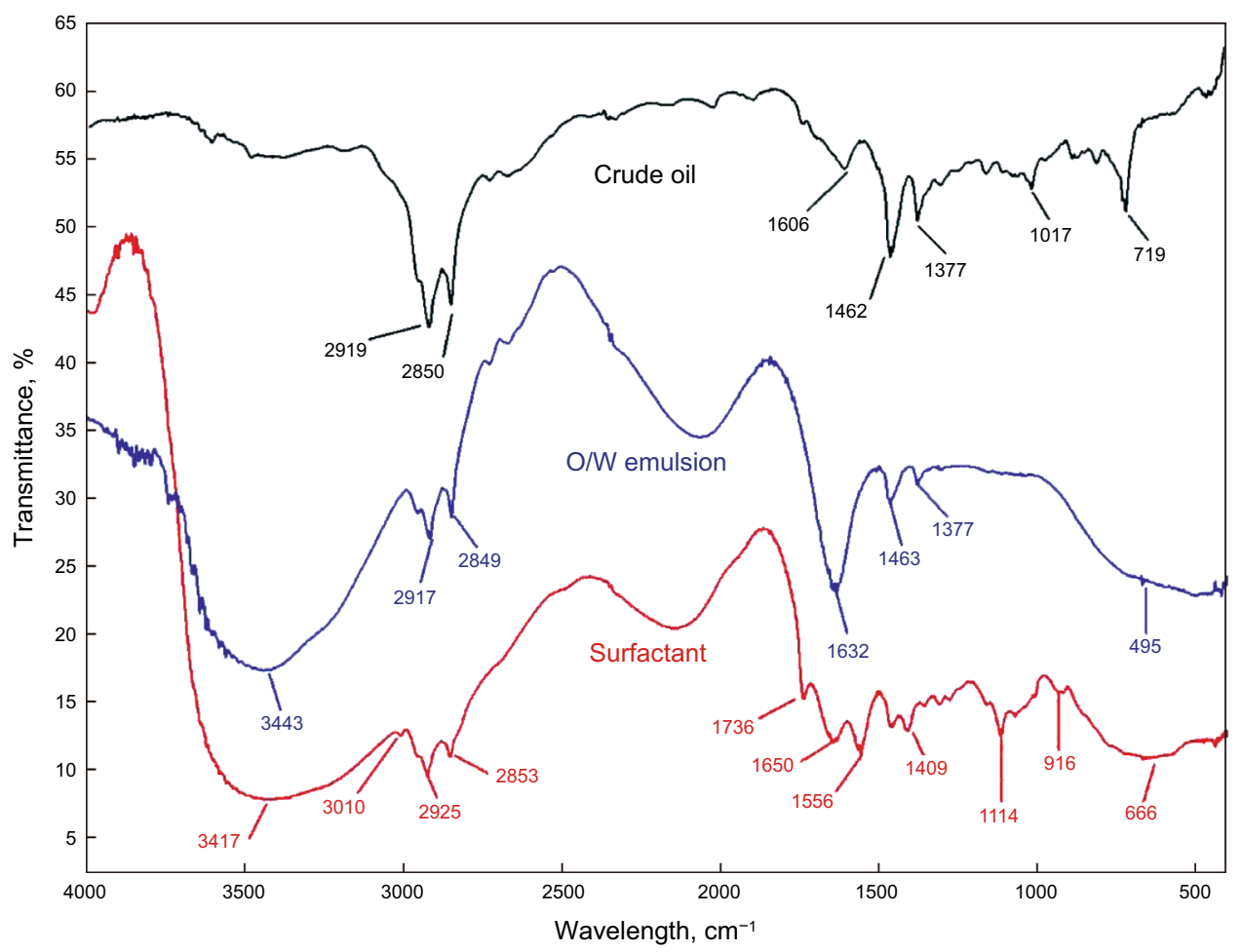

Fig. 1 FT-IR spectra of heavy crude oil, synthesized surfactant and prepared emulsion

Table 2 Wave number $\left(\mathrm{cm}^{-1}\right)$ for dominant peaks detected from FT-IR

\begin{tabular}{lllll}
\hline Functional group & Type of vibration & Crude oil & Surfactant & Emulsion $^{\text {a }}$ \\
\hline $\mathrm{O}-\mathrm{H}$ in water & Stretching & - & 3417 & 3443 \\
$=\mathrm{C}-\mathrm{H}$ in aromatics & Stretching & - & 3010 & - \\
$\mathrm{C}-\mathrm{H}$ in $\mathrm{CH}_{3}, \mathrm{CH}_{2}$ & Asymmetric stretching & 2919 & 2925 & 2917 \\
$\mathrm{C}-\mathrm{H}$ in $\mathrm{CH}_{3}, \mathrm{CH}_{2}$ & Symmetric stretching & 2850 & 2853 & 2849 \\
$\mathrm{C}=\mathrm{C}$ in alkene/aromatic nuclei & Stretching & 1606 & 1650 & 1632 \\
Unsaturated C=C & In-plane bending & 1017 & 916 & - \\
$\mathrm{C}=\mathrm{O}$ in ester & Stretching & - & 1736 & - \\
$\mathrm{C}-\mathrm{O}$ in ester & Stretching & - & 1114 & - \\
$\mathrm{C}-\mathrm{H}$ in $\mathrm{CH}_{3}, \mathrm{CH}_{2}$ & Symmetric bending & 1462,1377 & 1409 & 1463 \\
$-\left(\mathrm{CH}_{2}\right)_{n}^{-}$ & Rocking & 719 & 666 & 495 \\
\hline
\end{tabular}

${ }^{\mathrm{a}}$ Emulsion with $60 \%$ oil content and $2 \mathrm{wt} \%$ surfactant

\subsection{Rheological behaviour of heavy crude oil and prepared emulsions}

Flow behaviour of the heavy crude oil and emulsions was investigated in a rate-controlled (CR) mode over a shear rate range of $100-1000 \mathrm{~s}^{-1}$. The rheometer provided flow behaviour curves as both shear stress vs. shear rate and apparent viscosity vs. shear rate, along with respective data. Figure 2 shows the rheological behaviour of heavy crude oil and prepared emulsions by varying the oil content at a constant surfactant concentration $(2 \mathrm{wt} \%)$, measured at two gaps using parallel-plate geometry. Non-Newtonian behaviour of the shear-thinning profile was observed for heavy crude oil. For parallel-plate measurements at two gaps, instead of coinciding, lower apparent viscosity values were observed at lower gap size (at $500-\mu \mathrm{m}$ gap) for each emulsion over the range of shear rate studied due to occurrence of the wall slip effect. However, all data points from both gaps appeared to fall close to a single curve, indicating the slight possibility of wall slip. Apparent wall slip or wall depletion effects are observed for concentrated emulsion systems in rheometers due to displacement of the dispersed phase away from the solid boundaries (walls), and this displacement of the dispersed phase is caused due 


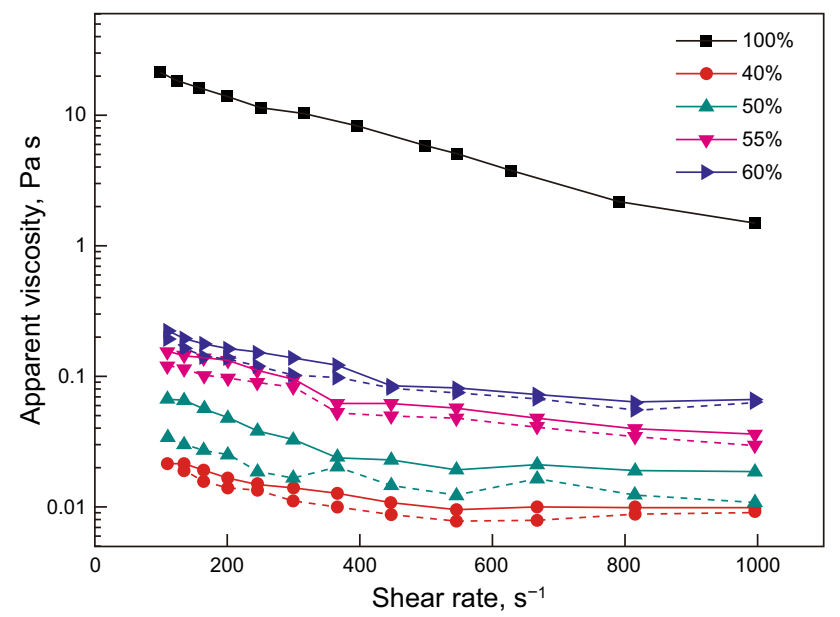

Fig. 2 Influence of oil content on the rheology of the emulsions at $2 \mathrm{wt} \%$ surfactant, measured at $25{ }^{\circ} \mathrm{C}$. Solid and dashed lines represent data at 750 - and $500-\mu \mathrm{m}$ gaps, respectively

to action of various physicochemical forces (Barnes 1995). The presence of wall slip poses a special problem while measuring actual rheological properties of emulsions. During rheological measurement of oil-in-water emulsions, depletion of the oil phase with an increase in shear stress leaves the low-viscosity liquid (continuous phase) adjacent to the boundary; thus, viscosities observed in such conditions are much lower than the actual ones (Pal 2000). However, during pipeline transportation of emulsions, due to slip, dispersed particles will be displaced away (towards centre, region of low shear) from the smooth solid wall of pipelines and facilitate the flow; therefore, estimation of actual rheological properties of an emulsion is important for industries involved in pipeline transportation. Apart from the geometry and shear rate used for measurement, possibility of wall slip also depends on the size of dispersed droplets in an emulsion. Lower dispersed droplet size lessens the chances of occurrence of wall slip inside the rheometer (Barnes 1995). All emulsions studied in this work possessed droplet sizes lower than $400 \mathrm{~nm}$, discussed in Sect. 3.8, which also suggests lower chances of wall slip.

Zahirovic et al. (2009) utilized the parallel-plate geometry at different gap sizes for very low apparent shear rate up to $1.0 \mathrm{~s}^{-1}$ and the vane geometry for shear rate further up to $100 \mathrm{~s}^{-1}$, in their study of ammonium nitratein-diesel oil emulsion. We have considered the high shear rate in our study because in most crude oil transportation pipelines actual flow takes place at shear rates around $500 \mathrm{~s}^{-1}$, where the shear rate near or on the pipe wall may be even higher (Azodi and Nazar 2013a; Johnsen and Rønningsen 2003). Since rheological measurement carried out at a bigger gap size is relatively less prone to wall slip (Pal 2000), results obtained at higher gap size $(750 \mu \mathrm{m})$ are further discussed here. However, results obtained at both gap sizes are comparatively presented in Table 3 as the degree of viscosity reduction at $546 \mathrm{~s}^{-1}$ shear rate. Up to $50 \%$ oil content, emulsions showed close to Newtonian behaviour, whereas, when the oil content further increased, they started to behave as non-Newtonian shear-thinning fluids. Shear-thinning behaviour suggests that the emulsion viscosity decreased as the pumping pressure increased. At high shear rate $\left(546 \mathrm{~s}^{-1}\right)$, the apparent viscosity of heavy crude oil was found to be $5081 \mathrm{mPa}$ s, whereas, after an emulsion was formed with $40 \%$ oil content, the emulsion viscosity reduced dramatically by $99.8 \%$ and reached $9.5 \mathrm{mPa}$ s. Furthermore, an increase in the oil content led to an increase in the emulsion viscosity. At $60 \%$ oil content, the emulsion viscosity increased to $81.2 \mathrm{mPa} \mathrm{s}$, where the degree of viscosity reduction was around $98.4 \%$. Further increase in the oil content led to an inversion of the $\mathrm{O} / \mathrm{W}$ emulsion into a W/O emulsion. From the results observed and considering the maximum throughput of oil through pipelines, it is clear that the optimum volume of oil was $60 \%$ for preparing a stable emulsion with acceptable viscosity.

At $60 \%$ oil content, the optimum amount of surfactant required to stabilize emulsions with acceptable viscosity was determined by measuring the rheology of emulsions of various surfactant concentrations. Figure 3 shows the effect of surfactant concentration on the rheology of emulsions, measured at two gaps using the parallel-plate geometry. Results obtained at both gap sizes are comparatively presented in Table 4, and results at $750 \mu \mathrm{m}$ are further discussed. As the surfactant concentration decreased from $2 \mathrm{wt} \%$ to $1 \mathrm{wt} \%$, the apparent viscosity of emulsions also decreased. At $1 \mathrm{wt} \%$ surfactant, the emulsion viscosity was reduced to approximately $99.3 \%$. However, at higher concentrations ( $3 \mathrm{wt} \%$ surfactant), the emulsion viscosity was $98.6 \mathrm{mPa} \mathrm{s}$, reduced by $98.0 \%$. This could be attributed to the fact that higher emulsifier concentration decreases the interfacial tension between oil and water, which leads to formation of smaller oil droplets. As a result of a decrease in droplet sizes, the number of droplets contacting water surface increases which ultimately increases the emulsion viscosity (Azodi and Nazar 2013b). It is not economical to use a large amount of surfactant. On the other hand, stability of the emulsion at lower surfactant concentration is another important factor to choose an optimum concentration.

\subsection{Interfacial tension analysis}

Surfactant effectiveness as an emulsifier is most importantly evaluated by its ability to decrease the IFT between crude oil and water. Figure 4 demonstrates the equilibrium IFT values between heavy crude oil (diluted) and the aqueous phase at various surfactant concentrations. It was 
Table 3 Viscosity reduction in emulsions of different oil contents at two gap sizes and $546 \mathrm{~s}^{-1}$ shear rate

\begin{tabular}{|c|c|c|c|c|}
\hline \multirow[t]{3}{*}{ Oil content, \% } & \multicolumn{4}{|l|}{ Parallel-plate geometry } \\
\hline & \multicolumn{2}{|l|}{$750-\mu \mathrm{m}$ gap } & \multicolumn{2}{|l|}{$500-\mu \mathrm{m}$ gap } \\
\hline & Apparent viscosity, $\mathrm{mPa} s$ & Viscosity reduction, $\%$ & Apparent viscosity, $\mathrm{mPa} \mathrm{s}$ & Viscosity reduction, $\%$ \\
\hline 60 & 81.2 & 98.4 & 75.4 & 98.5 \\
\hline 55 & 57.2 & 98.9 & 48.3 & 99.0 \\
\hline 50 & 19.4 & 99.6 & 12.4 & 99.7 \\
\hline 40 & 9.5 & 99.8 & 7.9 & 99.8 \\
\hline
\end{tabular}

Apparent viscosity of heavy crude oil is $5081 \mathrm{mPa} \mathrm{s}$

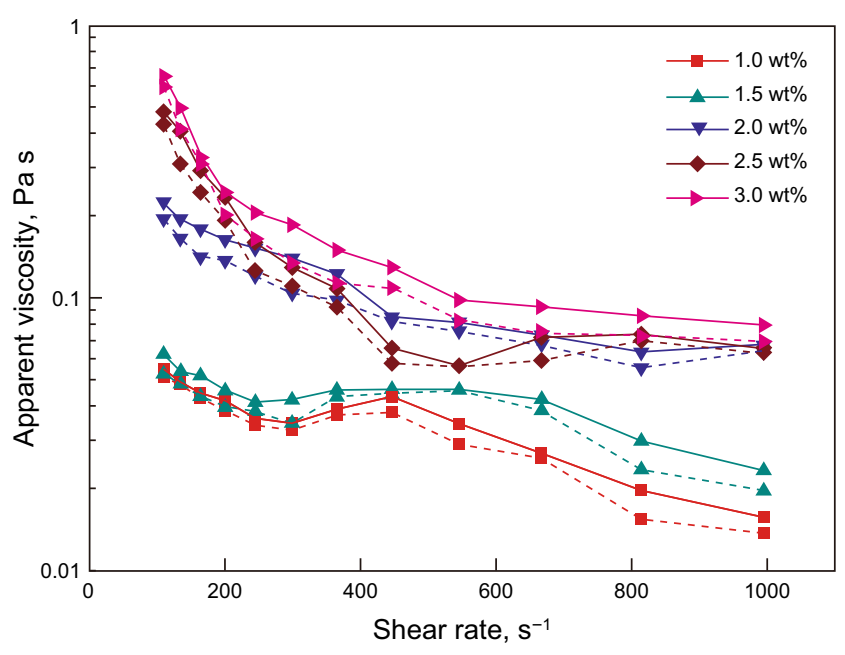

Fig. 3 Influence of surfactant concentration on the rheology of emulsions of $60 \%$ oil content, measured at $25{ }^{\circ} \mathrm{C}$. Solid and dashed lines represent data at 750 - and $500-\mu \mathrm{m}$ gaps, respectively

observed that with increasing surfactant concentration in the aqueous phase, IFT values decreased efficiently. IFT between diluted crude and water with no surfactant was around $6.15 \mathrm{mN} / \mathrm{m}$ and decreased to $1.10 \mathrm{mN} / \mathrm{m}$ after

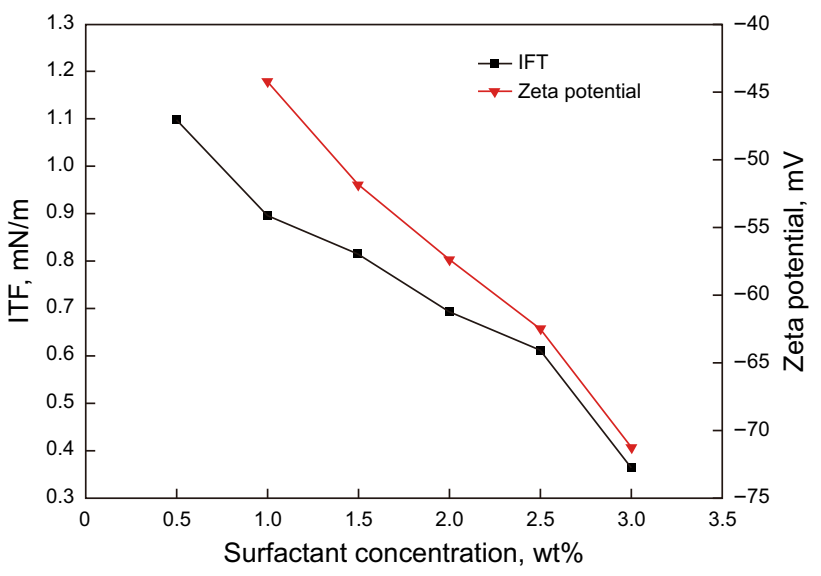

Fig. 4 IFT between crude oil and the aqueous phase and zeta potential as a function of surfactant concentration

$0.5 \mathrm{wt} \%$ surfactant addition. At $2 \mathrm{wt} \%$ surfactant, the IFT value decreased to $0.69 \mathrm{mN} / \mathrm{m}$, whereas at $3 \mathrm{wt} \%$, IFT reached to $0.37 \mathrm{mN} / \mathrm{m}$. The decreased IFT value contributed largely to a subsequent decrease in the drop size of dispersed crude oil. As a result of decreased particle size distribution, viscosity as well as the stability of the emulsion increased.

Table 4 Viscosity reduction in emulsions of different surfactant concentrations at two gap sizes and $546 \mathrm{~s}^{-1}$ shear rate

\begin{tabular}{|c|c|c|c|c|}
\hline \multirow[t]{3}{*}{ Surfactant concentration, wt $\%$} & \multicolumn{4}{|l|}{ Parallel-plate geometry } \\
\hline & \multicolumn{2}{|l|}{$750-\mu \mathrm{m}$ gap } & \multicolumn{2}{|l|}{$500-\mu \mathrm{m}$ gap } \\
\hline & Apparent viscosity, $\mathrm{mPa} \mathrm{s}$ & Viscosity reduction, $\%$ & Apparent viscosity, $\mathrm{mPa} s$ & Viscosity reduction, $\%$ \\
\hline 1.0 & 34.4 & 99.3 & 28.9 & 99.4 \\
\hline 1.5 & 46.1 & 99.1 & 45.8 & 99.1 \\
\hline 2.0 & 81.2 & 98.4 & 75.4 & 98.5 \\
\hline 2.5 & 56.2 & 98.9 & 55.9 & 98.9 \\
\hline 3.0 & 98.6 & 98.0 & 82.8 & 98.4 \\
\hline
\end{tabular}

Apparent viscosity of heavy crude oil is $5081 \mathrm{mPa} \mathrm{s}$ 


\subsection{Zeta potential analysis}

The zeta potential measurement helps in predicting emulsion stability by predicting the tendency of the emulsion to coalesce or flocculate. It characterizes distance between the emulsion droplets by calculating the electric charge on the surface of droplets. A higher absolute value of the zeta potential (either negative or positive) is interpreted as meaning there is higher charge on the droplets, which results in greater chances of them repelling each other and avoiding coalescence and flocculation. A lesser charge on the droplets allows them to come closer and coalesce/ flocculate (Jha et al. 2015). Figure 4 summarizes the effect on zeta potential of $\mathrm{O} / \mathrm{W}$ emulsions with increasing surfactant concentration. It was observed that the absolute value of zeta potential increased from 44.3 to $71.2 \mathrm{mV}$ as the surfactant concentration increased from $1 \mathrm{wt} \%$ to $3 \mathrm{wt} \%$ in the emulsion. These results suggest that with an increase in the surfactant concentration, the charge concentration on emulsion droplets also increased which led to production of a stable emulsion.

\subsection{Stability of emulsions}

Emulsion stability is a very important parameter which depends on factors like concentrations of oil/water and their density difference, water phase viscosity, salinity and $\mathrm{pH}$, choice and amount of surfactant, size of dispersed oil droplets, preparation method and duration and temperature of homogenization ( $\mathrm{Lim}$ et al. 2015). Based on water separation observed after 6 days at different temperatures, the emulsion stability is plotted in Figs. 5 and 6, respectively, against variations in oil content and surfactant concentration. It was observed from the results that

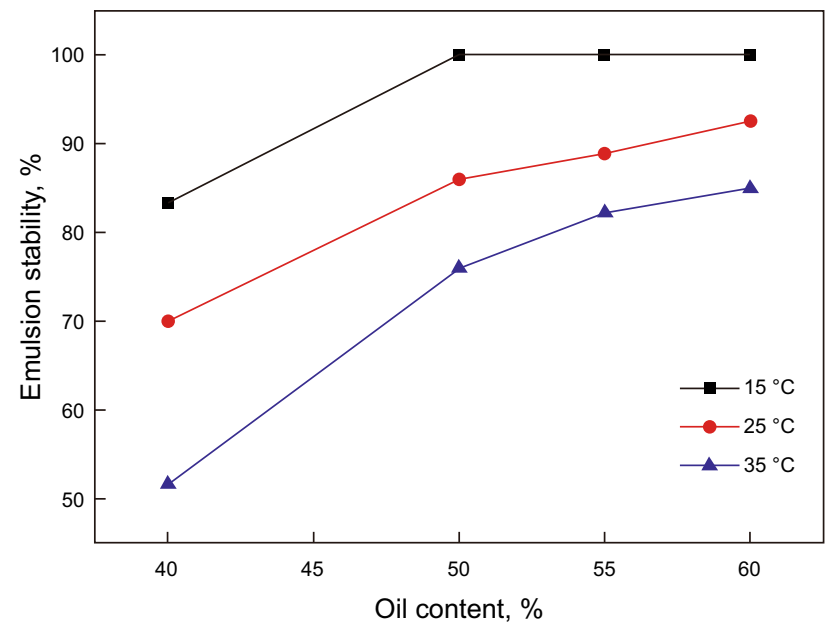

Fig. 5 Emulsion stability as a function of oil content at different temperatures ( $2 \mathrm{wt} \%$ surfactant) increases in both oil content as well as surfactant concentration led to an increase in the emulsion stability. On the other hand, temperature also played a very important role in the emulsion stability. Emulsion samples kept at lower temperatures showed higher stability than at higher temperatures. As the oil content in emulsion increased from $40 \%$ to $60 \%$ at $2 \mathrm{wt} \%$ surfactant, the emulsion stability increased from $51.7 \%$ to $85 \%$ at $35{ }^{\circ} \mathrm{C}$. When the temperature decreased from 35 to $15{ }^{\circ} \mathrm{C}$, the stability of the emulsion of $40 \%$ oil increased from $51.7 \%$ to $83.3 \%$ and for the emulsion of oil content above $40 \%, 100 \%$ stability was achieved. The effect of temperature can be explained by the fact that a decrease in temperature leads to a decrease in interfacial tension between oil and water. As a result, the decrease in internal energy of the molecules may decrease the pressure required to induce the interfacial film thinning and ultimately increases the coalescence time (Liyana et al. 2014).

The emulsions with $60 \%$ oil content were completely stable at $15{ }^{\circ} \mathrm{C}$, despite variation in surfactant concentration from $1 \mathrm{wt} \%$ to $3 \mathrm{wt} \%$. However, when the temperature increased to $25{ }^{\circ} \mathrm{C}$, the stability of emulsion with $1 \mathrm{wt} \%$ surfactant reduced to $82.5 \%$, and furthermore reduced to $70 \%$ at $35{ }^{\circ} \mathrm{C}$. Again, an increase in the stability at higher temperatures was achieved by increasing the surfactant concentration. The emulsion with $3 \mathrm{wt} \%$ surfactant was found to achieve stability around $95.0 \%$ and $92.5 \%$ at 25 and $35{ }^{\circ} \mathrm{C}$, respectively. An increase in the surfactant concentration results in an increasing number of surfactant molecules absorbed at the oil/water interface which provides a barrier to the coalescence of dispersed oil droplets, thus stabilizing the emulsion (Zaki 1997). Additionally, application of ultrasonic waves causes formation of droplets with smaller sizes, which increases the total interfacial area allowing more particle-to-particle interaction, and

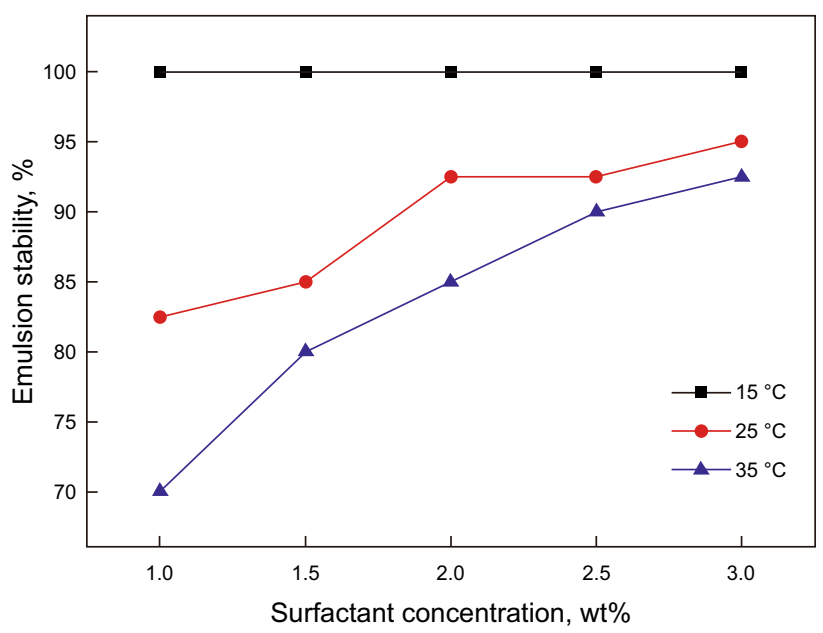

Fig. 6 Emulsion stability as a function of surfactant concentration at different temperatures (60\% oil content) 
finally leads to enhancing the emulsion stability. Considering the stability as well as viscosity of the emulsion of $60 \%$ oil content, $2 \mathrm{wt} \%$ surfactant can be used to prepare an efficient emulsion at $25{ }^{\circ} \mathrm{C}$. However, for lower temperatures, the surfactant concentration can also be less than $2 \mathrm{wt} \%$.

\subsection{Size distribution of oil droplets in emulsions}

Droplet size distribution is one of the important parameters that influence the rheology as well as the stability of the emulsion. This parameter is greatly affected by oil/water ratio, selection and concentration of surfactant and emulsification technique. Several authors previously have reported that the use of ultrasonic waves leads to production of emulsion with relatively smaller dispersed phase droplets than by a mechanical homogenizing method (Abismail et al. 1999; Lin and Chen 2006). Results of the volume droplet size distribution of $\mathrm{O} / \mathrm{W}$ emulsions at various oil content and surfactant concentration are plotted in Figs. 7 and 8, respectively.

Figure 7 shows that as the oil content of the emulsion increased, the size of dispersed oil droplets in the emulsion decreased. The emulsion with $40 \%$ oil had droplet sizes in a range of $164-342 \mathrm{~nm}$ in diameter, whereas, when the oil content increased to $60 \%$, the size range of droplets decreased to $122-295 \mathrm{~nm}$. From Fig. 8, it is clear that an increase in the surfactant concentration allowed the production of smaller oil droplets in the emulsion. The emulsion with $1 \mathrm{wt} \%$ surfactant had droplet sizes in a range of 164 to $396 \mathrm{~nm}$, whereas, when the surfactant concentration increased up to $3 \mathrm{wt} \%$, the size of dispersed droplets tended to decrease to $105-255 \mathrm{~nm}$. As been discussed previously, an increase in the surfactant concentration

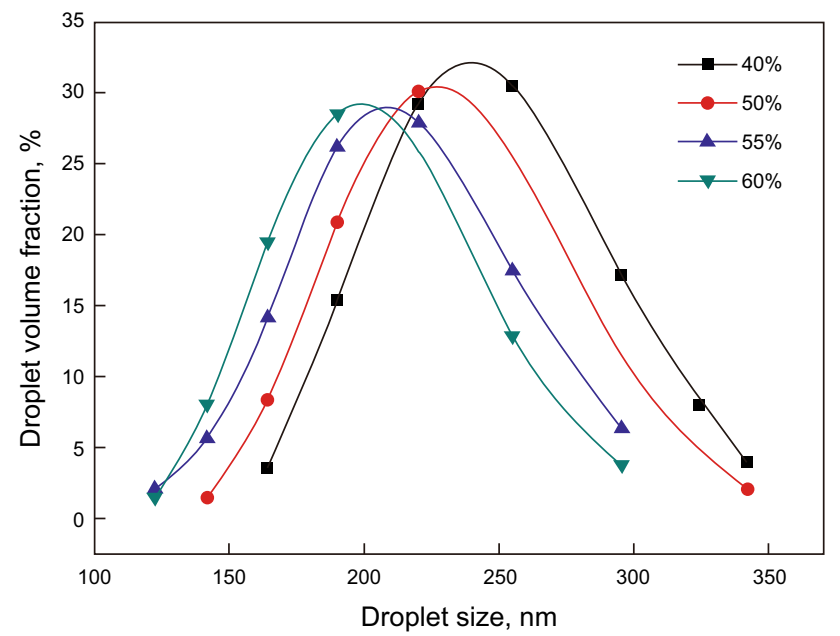

Fig. 7 Droplet size distribution of emulsions as a function of oil content (2wt\% surfactant)

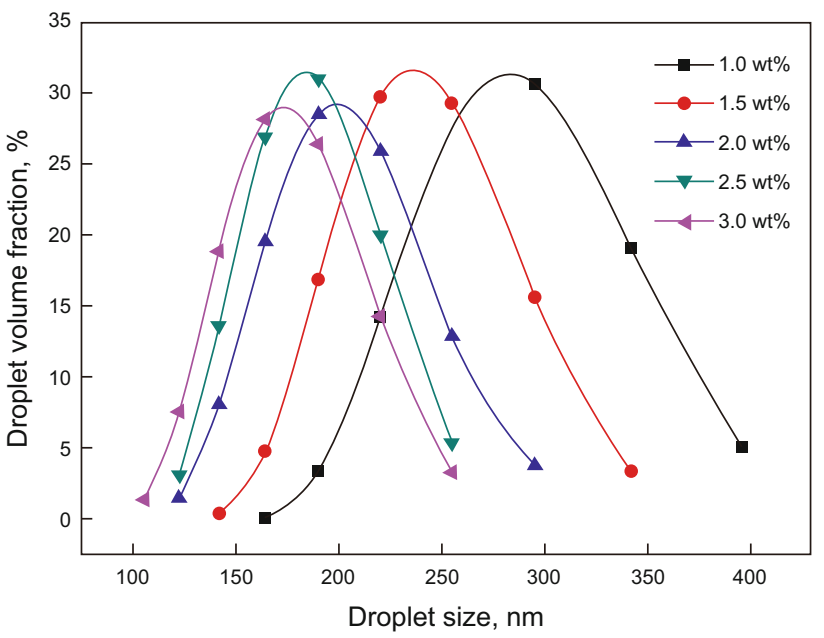

Fig. 8 Droplet size distribution of emulsions as a function of surfactant concentration

resulted in a decrease in IFT between oil and water, which further reduced the surface free energy required to increase the interfacial area and allowed the easier production of smaller oil droplets. A decrease in oil droplet size resulted in an increase in emulsion stability but also increased the emulsion viscosity, as seen in stability and viscosity results. Many authors previously have found the same effects of droplet size on viscosity and stability of emulsions (Kumar and Mahto 2016; Pal 1996; Zaki 1997). It was also noted that all the prepared emulsions had droplet sizes less than $400 \mathrm{~nm}$.

\section{Conclusions}

1. Surfactant (TMSE) synthesized using sunflower oil was found to be a very effective emulsifying agent for preparation of $\mathrm{O} / \mathrm{W}$ emulsions, and it may be considered for use in heavy oil transportation processes in offshore.

2. The emulsions prepared with TMSE were found to be still flowing at even $1{ }^{\circ} \mathrm{C}$, which can be highly suitable for flow in cold environments.

3. Flow behaviour of heavy crude oil and most of the emulsions within the experimental range were nonNewtonian shear thinning.

4. Formation of an $\mathrm{O} / \mathrm{W}$ emulsion caused a tremendous decrease in the viscosity of crude oil. All emulsions showed viscosity lower than $200 \mathrm{mPa}$ s at $25{ }^{\circ} \mathrm{C}$ and higher shear rate, which is adequate for flow in offshore conditions.

5. Synthesized surfactant decreased the IFT between oil (diluted) and the aqueous phase by the order of tenfold and led to preparation of highly stable emulsions. 
6. Use of ultrasonic waves led to production of emulsions with oil droplets size less than $400 \mathrm{~nm}$, which promotes an increase in emulsion stability.

7. For this particular heavy crude oil, $60 \%$ oil content and 2 wt $\%$ surfactant concentration were found to be optimum values to produce a flowable and stable $\mathrm{O} / \mathrm{W}$ emulsion using the synthesized surfactant at $25{ }^{\circ} \mathrm{C}$. For lower temperatures, a stable emulsion can also be produced even at the surfactant concentration less that $2 \mathrm{wt} \%$.

Acknowledgements Authors would like to gratefully acknowledge the Indian Institute of Technology (Indian School of Mines), Dhanbad for providing necessary laboratory facilities and financial support.

Open Access This article is distributed under the terms of the Creative Commons Attribution 4.0 International License (http://crea tivecommons.org/licenses/by/4.0/), which permits unrestricted use, distribution, and reproduction in any medium, provided you give appropriate credit to the original author(s) and the source, provide a link to the Creative Commons license, and indicate if changes were made.

\section{References}

Abismail B, Canselier JP, Wilhelm AM, Delmas H, Gourdon C. Emulsification by ultrasound: drop size distribution and stability. Ultrason Sonochem. 1999;6(1-2):75-83. doi:10.1016/S13504177(98)00027-3.

Ahmed NS, Nassar AM, Zaki NN, Gharieb HK. Formation of fluid heavy oil-in-water emulsions for pipeline transportation. Fuel. 1999;78(5):593-600. doi:10.1016/S0016-2361(98)00157-4.

Alcazar-Vara LA, Buenrostro-Gonzalez E. Characterization of the wax precipitation in Mexican crude oils. Fuel Process Technol. 2011;92(12):2366-74. doi:10.1016/j.fuproc.2011.08.012.

ASTM D1480-15. Standard test method for density and relative density (specific gravity) of viscous materials by Bingham pycnometer. 2015. doi:10.1520/D1480-15.

ASTM D4006-11. Standard test method for water in crude oil by distillation. 2011. doi:10.1520/D4006-11.

ASTM D5853-11. Standard test method for pour point of crude oils. 2011. doi: 10.1520/D5853-11.

Azodi M, Nazar ARS. Experimental design approach to investigate the effects of operating factors on the surface tension, viscosity, and stability of heavy crude oil-in-water emulsions. J Dispers Sci Technol. 2013a;34(2):273-82. doi:10.1080/01932691.2011. 646611.

Azodi M, Nazar ARS. An experimental study on factors affecting the heavy crude oil in water emulsions viscosity. J Pet Sci Eng. 2013b;106:1-8. doi:10.1016/j.petrol.2013.04.002.

Barnes HA. A review of the slip (wall depletion) of polymer solutions, emulsions and particle suspensions in viscometers: its cause, character, and cure. J Nonnewton Fluid Mech. 1995;56(3):221-51. doi:10.1016/0377-0257(94)01282-M.

Dantas Neto AA, Gomes EAS, Barros Neto EL, Dantas TNC, Moura CPAM. Determination of wax appearance temperature (WAT) in paraffin/solvent systems by photoelectric signal and viscosimetry. Braz J Pet Gas. 2009;3(4):149-57.

Dicharry C, Arla D, Sinquin A, Graciaa A, Bouriat P. Stability of water/crude oil emulsions based on interfacial dilatational rheology. J Colloid Interface Sci. 2006;297(2):785-91. doi:10. 1016/j.jcis.2005.10.069.

Hafiz AA, Abdou MI. Synthesis and evaluation of polytriethanolamine monooleates for oil-based muds. J Surfactants Deterg. 2003;6(3):243-51. doi:10.1007/s11743-003-0268-z.

Harrington KJ, D'Arcy-Evans C. Transesterification in situ of sunflower seed oil. Ind Eng Chem Prod Res. 1985;24(2):3148. doi:10.1021/i300018a027.

Jha NK, Jamal MS, Singh D, Prasad US. Characterization of crude oil of upper Assam field for flow assurance. In: SPE Saudi Arabia section technical symposium and exhibition, 21-24 April, AlKhobar, Saudi Arabia; 2014. doi:10.2118/172226-MS.

Jha PK, Mahto V, Saxena VK. Effects of carboxymethyl cellulose and tragacanth gum on the properties of emulsion-based drilling fluids. Can J Chem Eng. 2015;93(9):1577-87. doi:10.1002/cjce. 22259.

Johnsen EE, Rønningsen HP. Viscosity of "live" water-in-crude-oil emulsions: experimental work and validation of correlations. J Pet Sci Eng. 2003;38(1-2):23-36. doi:10.1016/S0920-4105(03) 00020-2.

Jiang J, Mei Z, Xu J, Sun D. Effect of inorganic electrolytes on the formation and the stability of water-in-oil (W/O) emulsions. Colloids Surf A Physicochem Eng Asp. 2013;429:82-90. doi:10. 1016/j.colsurfa.2013.03.039.

Kessick MA, Denis CES. Pipeline transportation of heavy crude oil. 1982. U.S. Patent No. 4,343,323.

Kumar S, Mahto V. Emulsification of Indian heavy crude oil in water for its efficient transportation through offshore pipelines. Chem Eng Res Des. 2016;115:34-43. doi:10.1016/j.cherd.2016.09.017.

Langevin D, Poteau S, Hénaut I, Argillier JF. Crude oil emulsion properties and their application to heavy oil transportation. Oil Gas Sci Technol. 2004;59(5):511-21.

Lim JS, Wong SF, Law MC, Samyudia Y, Dol SS. A review on the effects of emulsion on flow behaviours and common factors affecting the stability of emulsion. J Appl Sci. 2015;15(2):167-72.

Lin C-Y, Chen L-W. Emulsification characteristics of three- and twophase emulsions prepared by the ultrasonic emulsification method. Fuel Process Technol. 2006;87(4):309-17. doi:10. 1016/j.fuproc.2005.08.014.

Liyana M, Nour A, Rizauddin D, Gimbun J, Nurdin S. Stabilization and characterization of heavy crude oil-in-water $(\mathrm{O} / \mathrm{W})$ emulsions. IJRET Int J Res Eng Technol. 2014;3(2):489-96.

Martínez-Palou R, Mosqueira ML, Zapata-Rendón B, Mar-Juárez E, Bernal-Huicochea C, Clavel-López JC. Transportation of heavy and extra-heavy crude oil by pipeline: a review. J Pet Sci Eng. 2011;75(3-4):274-82. doi:10.1016/j.petrol.2010.11.020.

Pal R. Effect of droplet size on the rheology of emulsions. AIChE J. 1996;42(11):3181-90. doi:10.1002/aic.690421119.

Pal R. Slippage during the flow of emulsions in rheometers. Colloids Surf A Physicochem Eng Asp. 2000;162(1-3):55-66. doi:10. 1016/S0927-7757(99)00239-3.

Quiroga-Becerra H, Mejia-Miranda C, Laverde-Catano D, Hernandez-Lopez M, Gomez-Sanchez M. A kinetic study of esterification of naphthenic acids from a Columbian heavy crude oil. CT\&F Cienc Technol Futuro. 2012;4:21-32.

Sharma S, Mahto V, Sharma VP. Effect of flow improvers on rheological and microscopic properties of Indian waxy crude oil. Ind Eng Chem Res. 2014;53(12):4525-33. doi:10.1021/ ie $403050 y$.

Zahirovic S, Lubansky AS, Yeow YL, Boger DV. Obtaining the steady shear rheological properties and apparent wall slip velocity data of a water-in-oil emulsion from gap-dependent parallel plate viscometry data. Rheol Acta. 2009;29:48(2):221-9. doi:10.1007/s00397-008-0343-7. 
Zaki NN. Surfactant stabilized crude oil-in-water emulsions for pipeline transportation of viscous crude oils. Colloids Surf A Physicochem Eng Asp. 1997;125(1):19-25. doi:10.1016/S09277757(96)03768-5.
Zhao RB, Tang GQ, Kovscek AR. Modification of heavy-oil rheology via alkaline solutions. J Pet Sci Eng. 2013;103:41-50. doi:10. 1016/j.petrol.2013.02.009. 